\title{
Avascular Necrosis of the Intermedioradial Carpal Bone in a 6-Month-Old Dog
}

\author{
Dan D. Kenny ${ }^{10} \quad$ Turlough O’Neill ${ }^{1}$ \\ 1 Paragon Veterinary Referrals, Wakefield, United Kingdom \\ VCOT Open 2020;3:53-59.
}

\begin{abstract}
Address for correspondence Dan D. Kenny, BVSc, MRCVS, Paragon Veterinary Referrals, Wakefield, WF1 2DF, United Kingdom (e-mail: Dan.Kenny@paragonreferrals.co.uk).
\end{abstract}

\begin{abstract}
Keywords

- avascular necrosis

- pancarpal arthrodesis

- Legg-Calvé-Perthes disease

- Preiser's disease

- intermedioradial carpal bone

A 6-month-old neutered male dog presented for investigation of right thoracic limb lameness of 6-week duration following an acute injury. Radiography and computed tomography revealed focal osteolysis of the intermedioradial carpal bone. Histopathology of the bone revealed osteonecrosis, bone resorption, fibrous proliferation and new bone formation suggestive of avascular necrosis. Pancarpal arthrodesis was performed to stabilize the carpus and resulted in resolution of lameness and return to normal exercise. Avascular necrosis of carpal bones is rare and unreported in skeletally immature dogs. The imaging and histopathological changes in this dog's intermedioradial carpal bone bear strong similarity to Legg-Calvé-Perthes disease and the two presentations may have a similar traumatic vascular pathology.
\end{abstract}

\section{Introduction}

Legg-Calvé-Perthes disease (LCPD) is the most common manifestation of avascular or ischaemic necrosis (AVN) of bone in companion animals. ${ }^{1}$ It is characterized by a non-inflammatory local necrosis and lysis of the trabeculae within the femoral head and neck. Radiographically, the process appears as focal osteolysis followed by collapse of the subchondral bone, revascularization and bone remodelling in the femoral head. ${ }^{2}$ Although the aetiology is not completely understood, ischaemia resulting from vascular compression or compromise is proposed. ${ }^{1}$ Legg-Calvé-Perthes disease is most commonly seen in small breed dogs presenting with variable hindlimb lameness, between the age of 4 and 11 months. ${ }^{1}$

Here we describe a case of necrosis and osteolysis in the intermedioradial carpal bone of a skeletally immature dog suspected to have occurred as a result of trauma. The case bears histopathological and imaging similarities to LCPD as well as a human condition involving ischaemic necrosis of the scaphoid bone (Preiser's disease).

\section{Case Report}

A 6-month-old, $8 \mathrm{~kg}$, neutered male crossbreed dog was presented for investigation of an acute right thoracic limb lameness of 6-week duration believed to have started immediately after the dog had jumped from a step. Exercise restriction and oral administration of meloxicam (Metacam; Boehringer Ingelheim, UK) $0.05 \mathrm{mg} / \mathrm{kg}$ every 24 hours for 14 days and paracetamol codeine (Pardale V; Dechra, Shropshire) $10 \mathrm{mg} / \mathrm{kg}$ every 12 hours for 7 days failed to improve the lameness. Thoracic limb radiography performed 2 weeks prior to referral revealed no abnormalities.

At presentation the dog had a non-weight bearing right thoracic limb lameness with atrophy of the limb musculature. Moderate pain was elicited on hyperflexion and palpation of the dorsal and medial aspects of the right carpus; however, there was no observed joint instability. Physical examination findings were otherwise unremarkable.

Standard orthogonal radiographs of the right carpus were obtained under sedation. These revealed mottled osteolysis of the centrolateral region with a dorsal cortical defect of the intermedioradial carpal bone (-Fig. 1). There was also evidence of closure of the distal radial and ulnar physes. Comparative radiographs of the left carpus were unremarkable.

Computed tomographic (CT) imaging revealed focal osteolysis of the right intermedioradial carpal bone with associated osteopenia and muscle atrophy (-Figs. 2-4). Closure of the right distal ulnar physis as well as partial closure of the right distal radial physis was also noted.
License terms

Stuttgart · New York
DOI https://doi.org/

10.1055/s-0040-1713122. ISSN 2625-2325.
February 5, 2020

accepted

April 18, 2020 


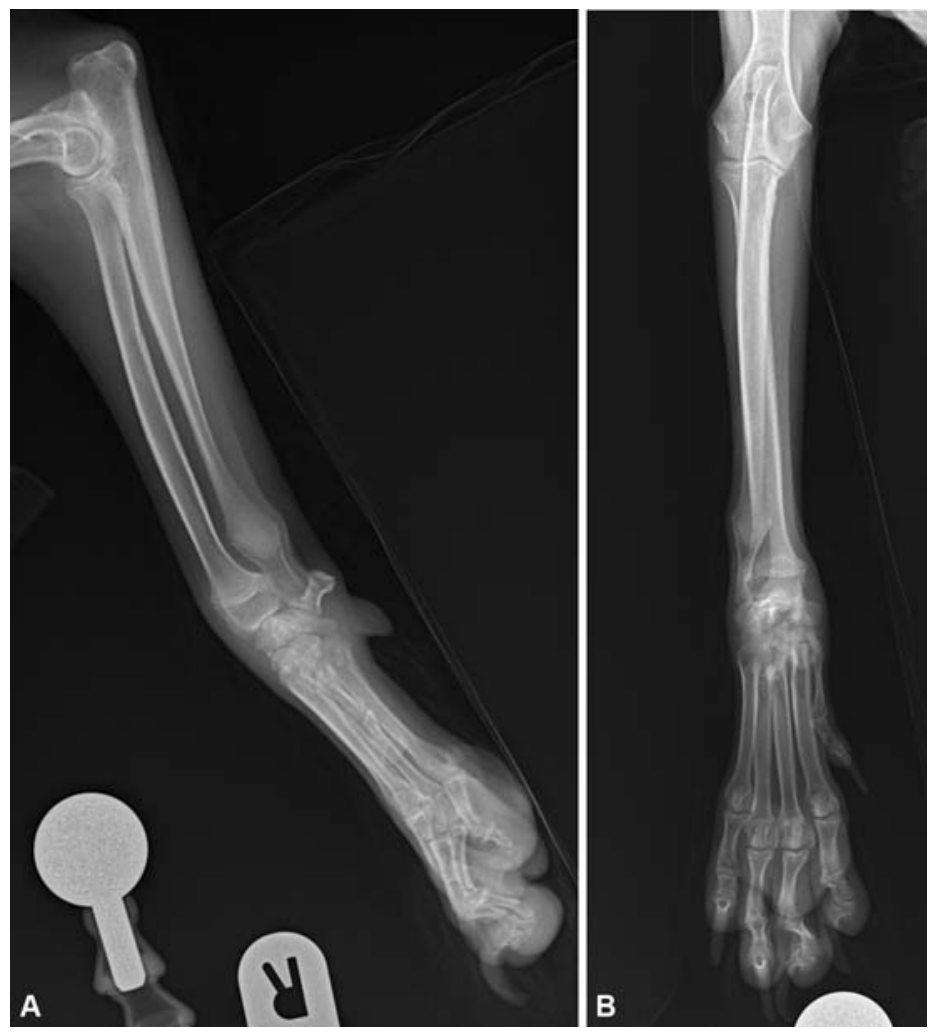

Fig. 1 Mediolateral and dorsopalmar radiographic projections of the right carpus illustrating mottled osteolysis of the centrolateral region of the intermedioradial carpal bone. A defect in the dorsal cortex of the intermedioradial carpal bone is also evident on the mediolateral view. Radiographic evidence of closure of the right distal ulnar physis is noted.

Antebrachiocarpal arthrocentesis was cytologically consistent with synovial hyperplasia with mild neutrophilic inflammation (-Fig. 5). A fine-needle aspirate from the right intermedioradial carpal bone revealed slight to moderate, chronic and active inflammation with a population of atypical cells interpreted to be osteoblasts (-Fig. 6). The clinical examination, diagnostic imaging and laboratory findings were suggestive of AVN of the right intermedioradial carpal bone. Given the conditions chronicity, discomfort and poor response to analgesia, surgical exploration and pancarpal arthrodesis was proposed to stabilize the joint.

The dog was anaesthetized and following a dorsal approach ${ }^{3}$ the right carpus was explored. The dorsal intermedioradial carpal bone was soft and had a significant defect in the cortical structure with erosion of the bone trabeculae especially in the centrolateral region. The remaining structure was a fragile shell of cortical bone lined on the articular surfaces with cartilage (-Fig. 7); a sample was taken for histopathological analysis. A lateral approach was made to the right distal ulna and $\sim 1 \mathrm{~cm}$ of bone was excised. Distal ulnar ostectomy was performed to mitigate against the sequelae of the closed distal radial and ulnar physes in the face of an open proximal radial growth plate; it also allowed the harvest of autogenous corticocancellous bone graft. A high-speed pneumatic burr (Minos A200; $3 \mathrm{M}$ ) was used to remove articular cartilage of the joint surfaces of the carpus to the level of subchondral bone. A $5 \mathrm{~mm}$ piece of excised ulna was used as corticocancellous autograft to fill the intermedioradial carpal bone defect. Freeze-dried demineral- ized bone matrix allograft (Canine allograft; Veterinary Tissue Bank) was packed into the debrided joint spaces.

Orthogonal plates were used to achieve stability. A 10hole $1.5 / 2.0 \mathrm{~mm}$ locking compression plate (LCP) (DePuySynthes Vet) was applied to the dorsal surface of the radius and metacarpal 3 and a $1.5 \mathrm{~mm} / 2.0 \mathrm{~mm}$ cuttable plate (Vetisco) was applied to the medial surface of the radius and metacarpal 2.

Postoperative radiographs confirmed good implant placement and alignment (- Fig. 8). Recovery was uneventful. The patient was discharged with oral meloxicam $0.05 \mathrm{mg} / \mathrm{kg}$ every 24 hours for 21 days, and oral paracetamol codeine $10 \mathrm{mg} / \mathrm{kg}$ every 12 hours for 5 days. The dog was cage rested for 4 weeks followed by a gradual increase in exercise.

Histopathology of the intermedioradial carpal bone fragment revealed sections composed of irregular trabeculae of lamellar bone. Osseous trabeculae were variably hypereosinophilic and acellular (necrotic). These necrotic fragments were bordered by a proliferative fibrous stroma and plump osteoclasts within lacunae, adjacent fibrous connective tissue frequently contained woven bone. Within intact adjacent trabeculae, there were moderate numbers of osteoclasts, plump osteoblasts lining the trabeculae and congested vasculature. Bordering the vasculature there were low numbers of neutrophils, lymphocytes and plasma cells ( - Fig. 9). These changes were consistent with AVN.

Ten weeks postoperatively the dog was exercising with no observable lameness. On examination, the dog was fully weight 

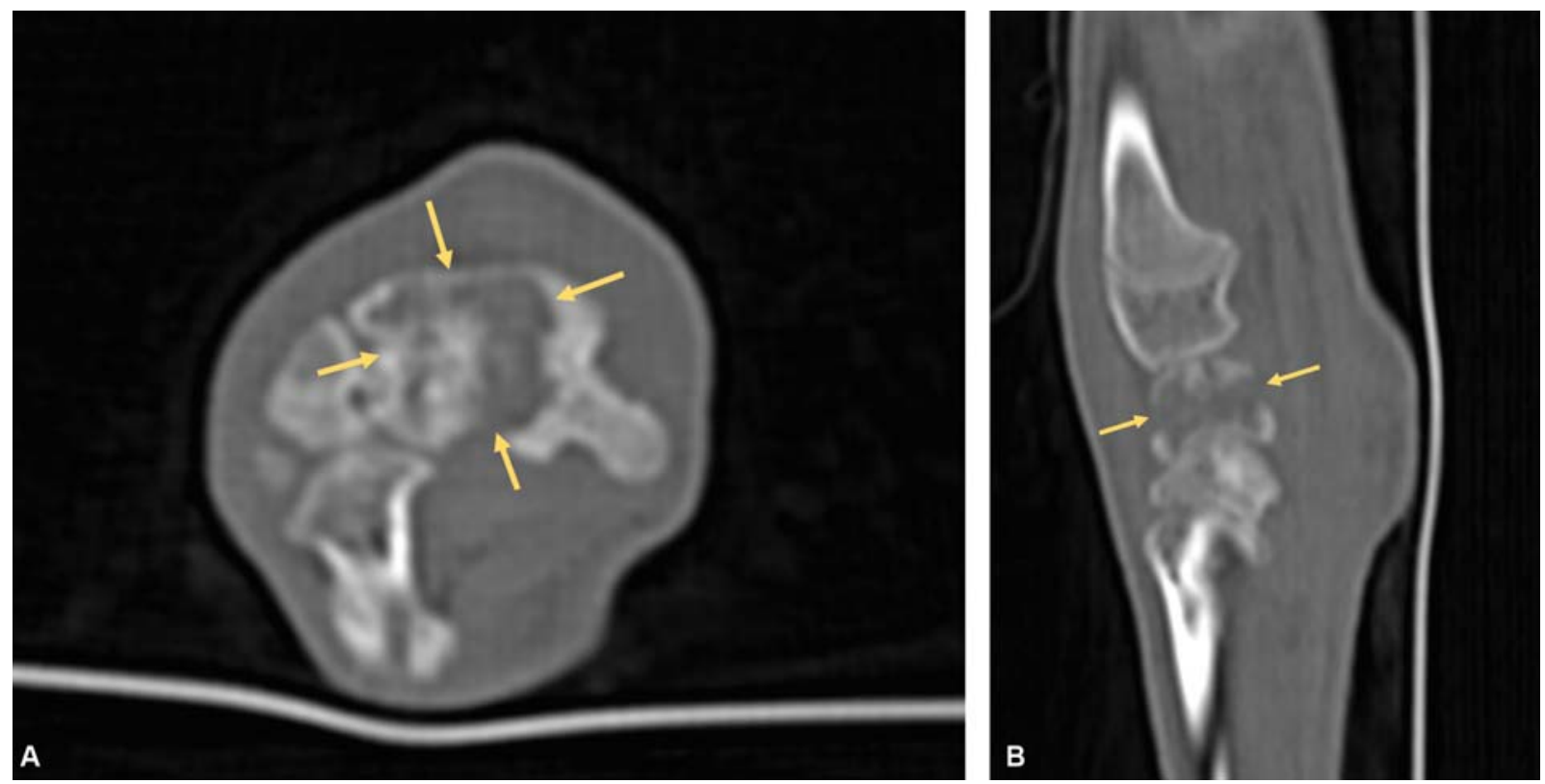

Fig. 2 Transverse computed tomographic image and sagittal reconstruction of the right carpus demonstrating focal bone lysis of the intermedioradial carpal bone (arrows).

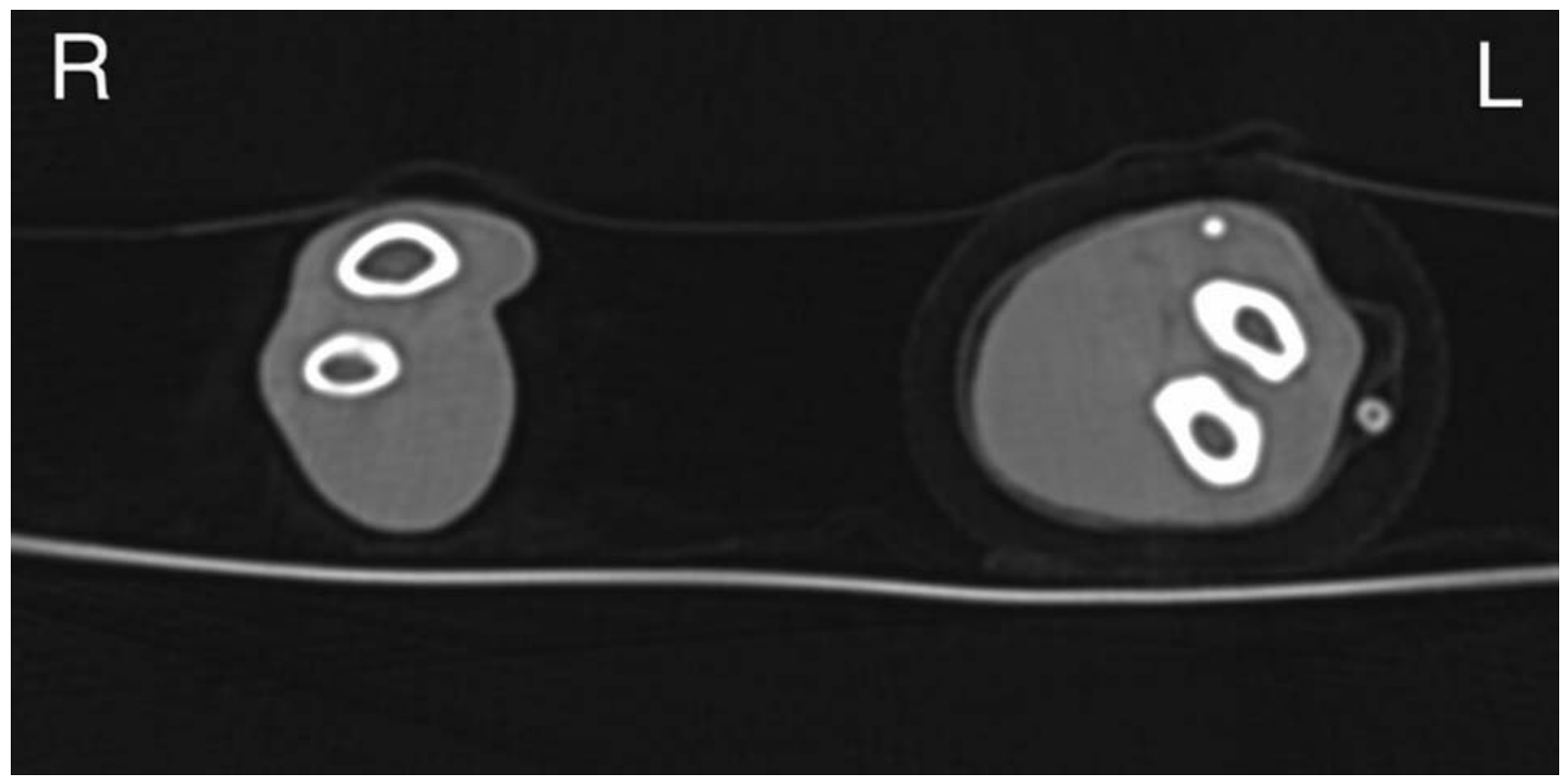

Fig. 3 Transverse computed tomographic image of left and right antebrachia illustrating muscle atrophy of the right antebrachium in comparison to the left. Radial and ulnar cortical thinning due to disuse osteopenia of the right thoracic limb is also evident (Image Courtesy: Paul Barthez, DACVR, DipECVDI, VEDIM, Luxembourg).

bearing on the right thoracic limb. The right carpus was stable, and no pain was apparent. Radiography revealed successful arthrodesis of the carpus with smooth dorsal periosteal bone remodelling associated with the proximal extent of the plate on the radius and metacarpal 3 distally (-Fig. 10). The dog was gradually returned to normal exercise.

\section{Discussion}

In dogs, AVN of carpal bones is rarely reported, with one case of an 8-year-old Staffordshire Bull Terrier assessed for a chronic and progressive history of thoracic limb lameness following a fall. ${ }^{4}$ Radiographically, the dog had evidence of osteolysis of the intermedioradial carpal bone and histopathological changes were consistent with AVN. The dog was treated with pancarpal arthrodesis which offered improvement in lameness and only a mild mechanical lameness was reported 12 weeks postoperatively. Idiopathic AVN of an accessory carpal bone has also been reported in a 6-year-old dog which was treated with excision of the accessory carpal bone and pancarpal arthrodesis. ${ }^{5}$

Avascular necrosis of the scaphoid (intermedioradial carpal) bone in humans (Preiser's disease) is a rare pathology causing pain and swelling around the dorsoradial wrist. ${ }^{6}$ Although it is recognized to occur following fractures of the scaphoid, ${ }^{7}$ it is currently described as idiopathic and other proposed causes include trauma, vascular damage, corticosteroid usage, 


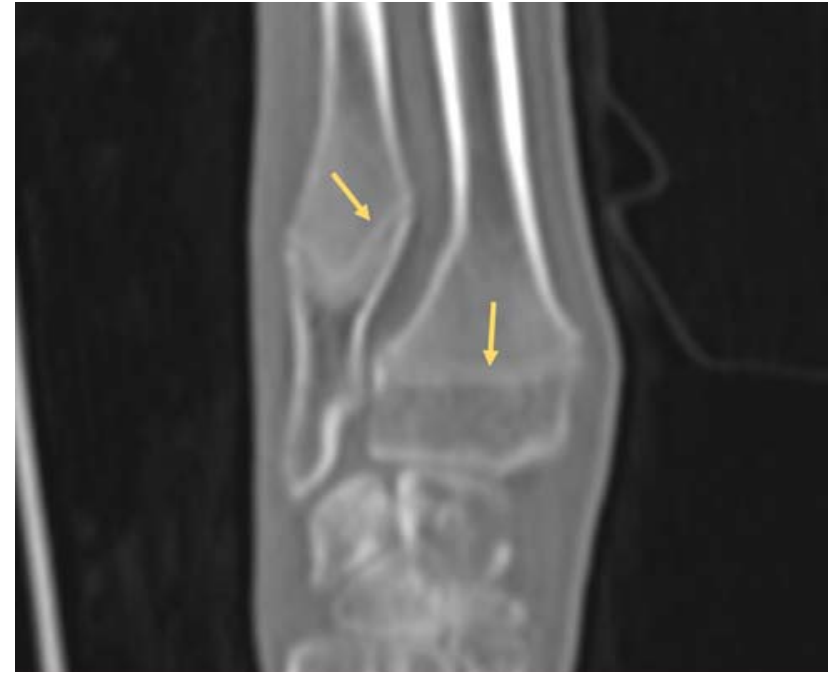

Fig. 4 Dorsal reconstruction computed tomographic image of the right carpus showing diffuse demineralization and closure of the distal radial and ulnar physis (arrows) (Image Courtesy: Paul Barthez, DACVR, DipECVDI, VEDIM, Luxembourg).

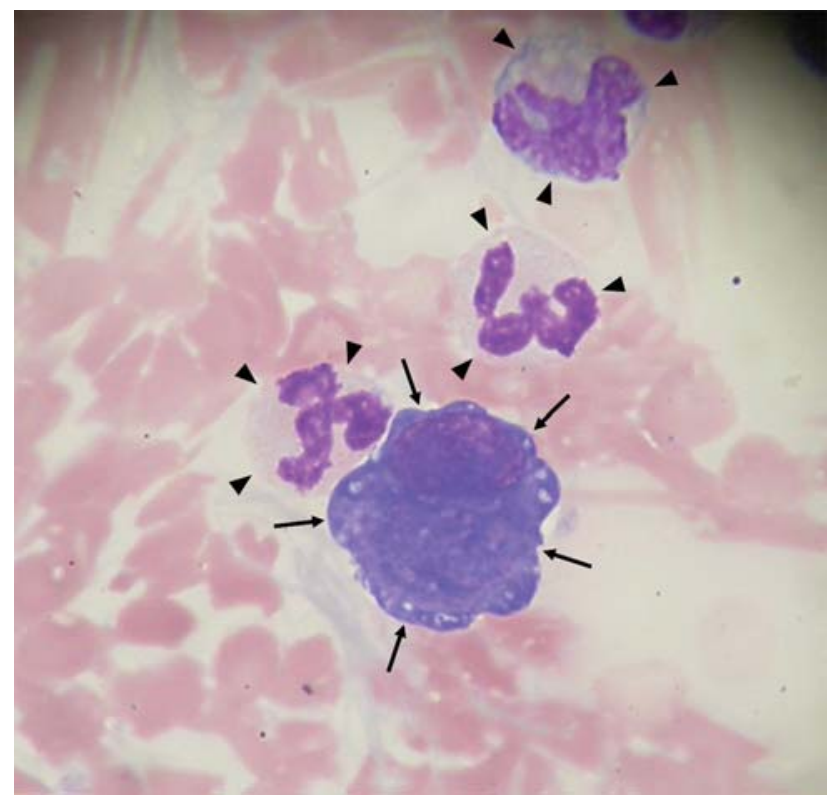

Fig. 5 Synovial fluid cytology consistent with synovial hyperplasia with mild neutrophilic inflammation. Three neutrophils (arrowheads) with a reactive, slightly hyperplastic and hypertrophic synovial lining cell (arrows). Modified Wright's stain 100x (oil) (Image Courtesy: Nick Marsh, BVSc, MRCVS, Syn Labs VPG, Exeter).

systemic disease and congenital mechanisms. ${ }^{8-10}$ Radiographically, there is evidence of fragmentation, sclerosis and erosion of the proximal pole of the scaphoid bone. ${ }^{8}$ Due to the rarity of the condition, management remains problematic and no consistent treatment guidelines exist.

In this case, the osteolytic radiographic appearance of the intermedioradial carpal bone was similar to that seen in LCPD. While collapse and remodelling had not occurred, the CT images clearly demonstrated the loss of bone trabeculae which is present in this condition. ${ }^{11}$ Additionally, a similar cytological and histopathological response of osteonecrosis, resorption of bone, fibrous proliferation and new bone formation was discovered in the intermedioradial carpal bone. These changes

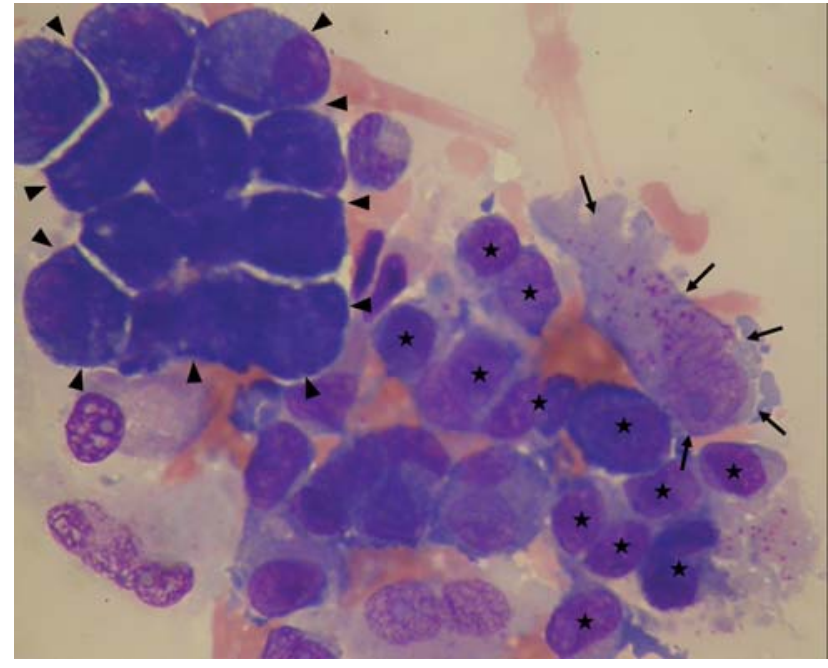

Fig. 6 Fine-needle aspirate taken from right intermedioradial carpal bone. Reactive mesenchymal cell (black arrow) with sparsely granulated cytoplasm, consistent with attempted healing. A few lymphocytes are also present (asterisk). A small cluster of osteoblast-like cells interpreted to be reactive or proliferative are present (arrowhead). The remainder of the cells, including a few binucleated cells, are consistent with synovial lining origin. Modified Wright's Stain, 100x (oil) (Image Courtesy: Nick Marsh, BVSc, MRCVS, Syn Labs VPG, Exeter).

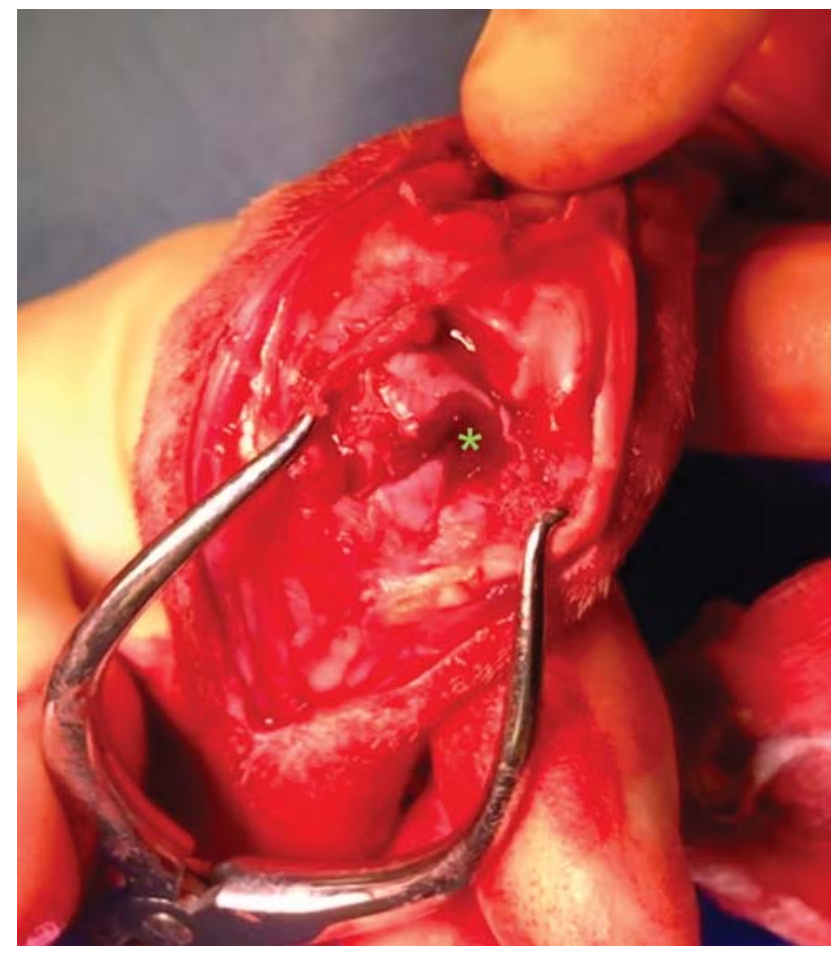

Fig. 7 Photograph of the gross intraoperative appearance of the intermedioradial carpal bone demonstrating loss of cranial cortex and osteolysis of trabecular bone concentrated in the centrolateral region of the bone (asterisk).

are characteristically present in LCPD and could be suggestive of a similar vascular involvement in aetiology.

Proposed causes for AVN in LCPD include trauma to the bone or blood supply, increased intracapsular pressure, infarction of the femoral head, infection, drug therapy, conformational 

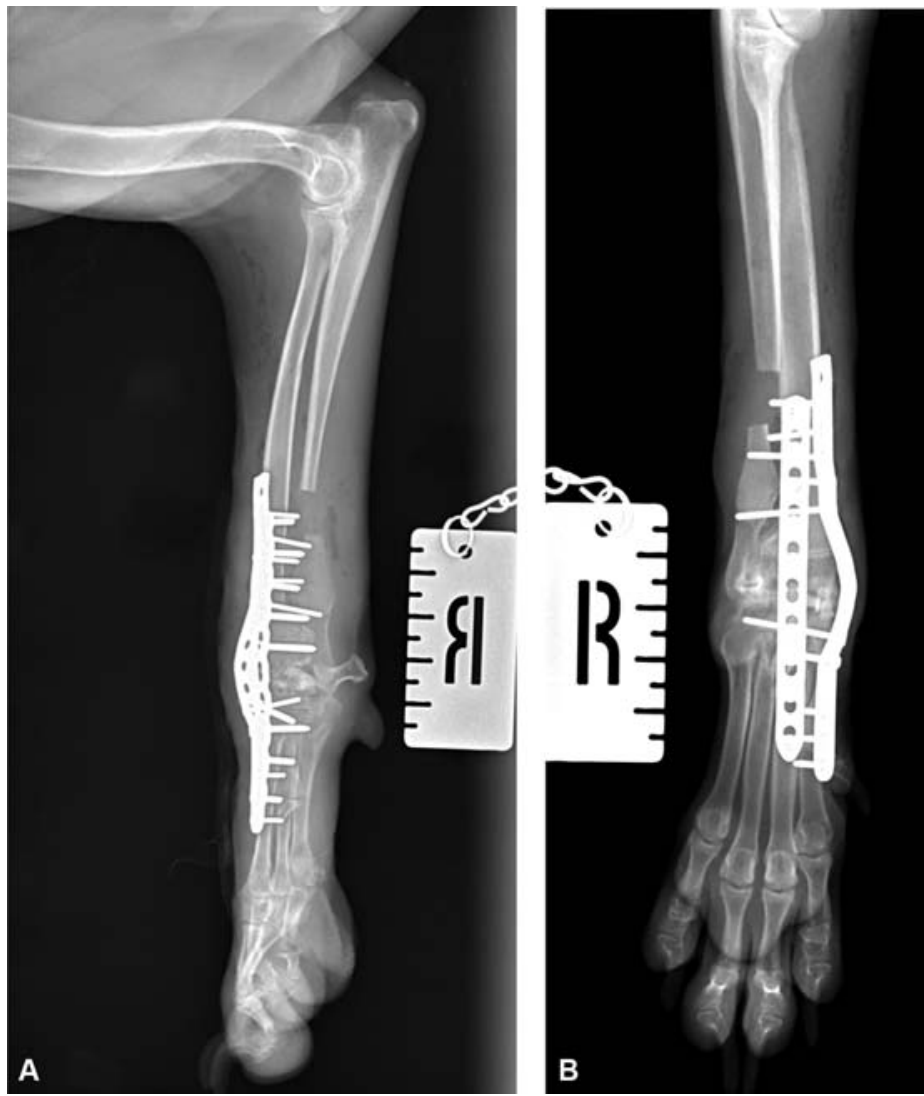

Fig. 8 Mediolateral and dorsopalmar radiographic projections of the right carpus immediately postoperatively, demonstrating distal ulnar ostectomy and orthogonal plating of the carpus.

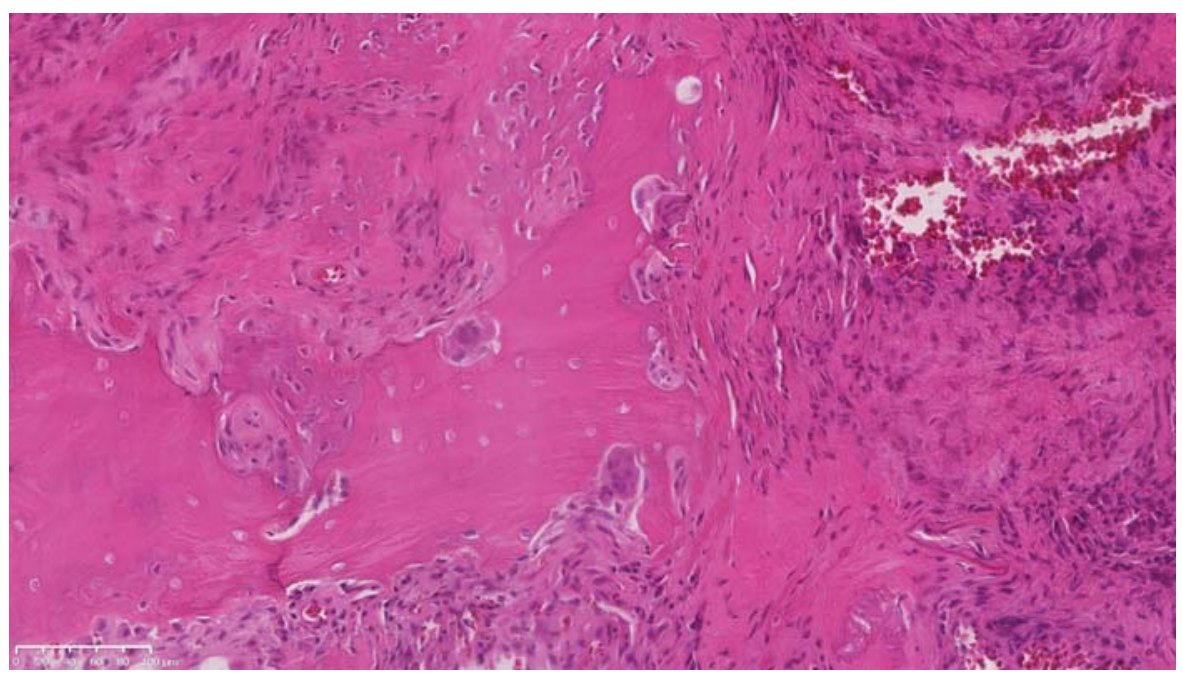

Fig. 9 Histopathological image illustrating resorbing necrotic bone bordered by proliferative stroma which exhibits new bone formation (Image Courtesy: SamBeck, BSc, BVSc, MVetMed, DipACVP, FRCPath, MRCVS, VPG Histology, Bristol).

abnormalities and hereditary or genetic factors. ${ }^{1,12,13}$ Given the patient history of compressive axial trauma immediately prior to lameness onset and CT evidence of distal radial and ulnar physeal closure, we hypothesized that the traumatic incident had contributed to development of AVN in this patient.

We were unable to find any studies detailing the origins of vascularity to the intermedioradial carpal bone; however, it is likely that the arterial blood supply to the dorsal centrolateral region is derived from the caudal interosseus ramus which forms the dorsal carpal rete. The central region of the bone may also be supplied by the 2,3-intercompartmental supraretinacular artery and the centromedial region supplied through the dorsal carpal branch of the radial artery. ${ }^{14,15}$

Kalainov and colleagues ${ }^{16}$ identified two distinct types of AVN in Preiser's disease, one localized to the proximal pole of the scaphoid and a generalized form. It is hypothesized that 


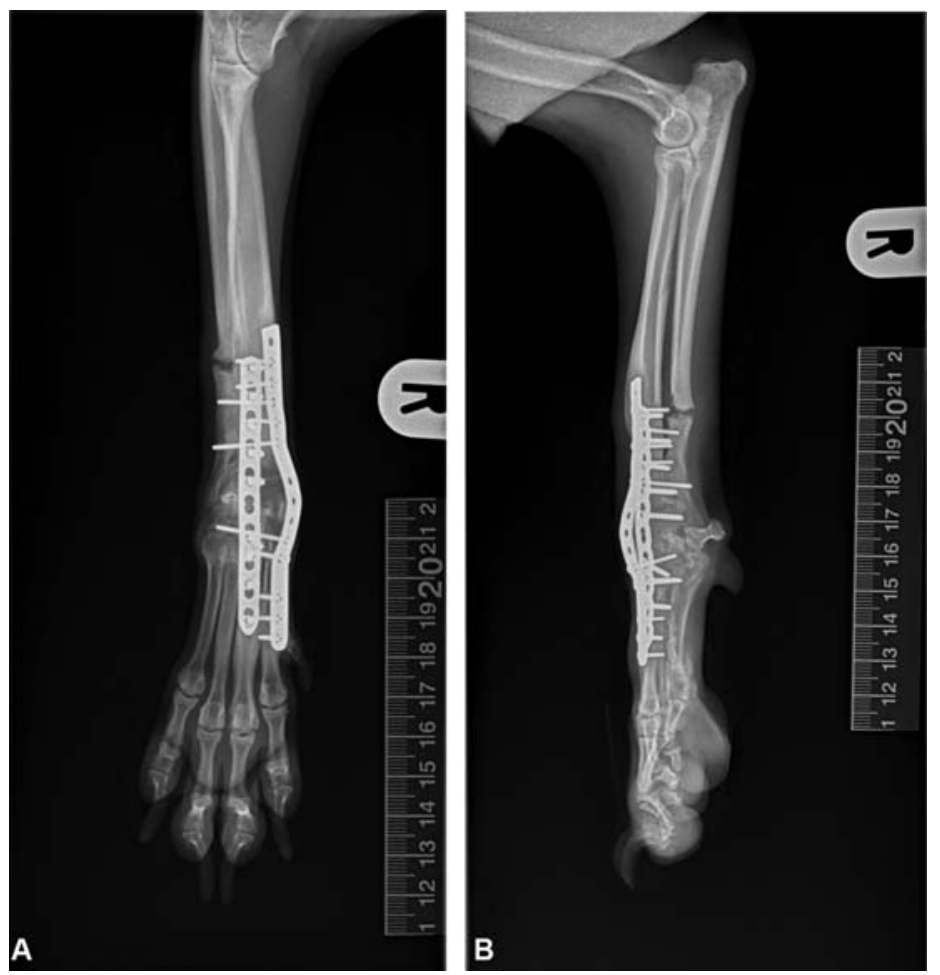

Fig. 10 Dorsopalmar and mediolateral right thoracic limb radiographs performed 10 weeks post-surgery illustrating successful arthrodesis of the right carpus with orthogonal plating. There is evidence of the distal ulnar ostectomy healing and there is no sign of obvious elbow incongruency.

damage to the dorsal vascular network which is the only blood supply to the proximal region of the scaphoid may explain the localized presentation. ${ }^{10}$ In this case, it is possible that the traumatic incident damaged or caused temporary occlusion to the one or more blood vessels supplying the intermedioradial carpal bone leading to AVN. Given the presence of focal osteolysis of the centrolateral portion of the bone, it is possible that it may have been the dorsal carpal rete that was affected. Similar to LCPD, it was suspected that only temporary vascular compromise rather than permanent insult was responsible for these changes as osteoblastic activity and reparative fibrosis were observed histologically. ${ }^{11}$ The dual mechanism and presence of collateral arterial blood supply may well be the reason for the paucity of reported cases of AVN of the intermedioradial carpal bone. Contrast CT and arteriography or magnetic resonance imaging would likely have provided further information about the integrity of the vascular supply to the intermedioradial carpal bone and could be considered in future research. ${ }^{17}$

The radiographic, CT and histopathological changes in this dog's intermedioradial carpal bone bear strong similarity to LCPD and the two presentations may have a similar traumatic vascular pathology.

Conflict of Interest

None declared.

\section{Acknowledgments}

The authors would like to thank Kathy Freeman DVM, BS, MS, PhD, DipECVCP, FRCPath MRCVS, Sam Beck, BSc, BVSc,
MVetMed, DipACVP, FRCPath, MRCVS and Nick Marsh, BVSc, MRCVS, for their assistance with cytological and histopathological analysis, and Paul Barthez, DACVR, DipECVDI, for provision of additional CT images.

\section{References}

1 DeCamp CE, Johnston SA, Déjardin LM, Schaefer SL. Legg-CalvéPerthes Disease. In: Brinker, Piermattei and Flo's Handbook of Small Animal Orthopaedics and Fracture repair. Fifth edition. St Louis, Missouri: Elsevier; 2006:513-515

2 Conzemius MG, Lotsikas P. Legg-Calvé-Perthes Disease. In: Bojrab MJ, Monnet E, eds. Mechanisms of Disease in Small Animal Surgery. Third edition. Jackson, Wyoming: Teton NewMedia; 2010:633-636

3 Johnson KA. The Forelimb. In: Johnson KA, ed. Piermattei's Atlas of Surgical Approaches to the Bones and Joints of the Dog and Cat. Fifth edition. St Louis, Missouri: Elsevier/Saunders; 2014:284-291

4 Aiken MJ, Stewart JE, Anderson AA. Avascular necrosis of the canine radial carpal bone: a condition analogous to Preiser's disease? J Small Anim Pract 2013;54(07):374-376

5 Harris KP, Langley-Hobbs SJ. Idiopathic ischemic necrosis of an accessory carpal bone in a dog. J Am Vet Med Assoc 2013;243(12): 1746-1750

6 Menth-Chiari WA, Poehling GG. Preiser's disease: arthroscopic treatment of avascular necrosis of the scaphoid. Arthroscopy 2000;16(02):208-213

7 Preiser G. Eine typische posttraumatische und zur spontanfraktur führende Ostitis des Naviculare carpi. Fortschr Geb Rontgenstr 1910;15:189-197

8 Vidal MA, Linscheid RL, Amadio PC, Dobyns JH. Preiser's disease. Ann Chir Main Memb Super 1991;10(03):227-235

9 Imam S, Aldridge C, Lyall H. Bilateral idiopathic avascular necrosis of the scaphoid: a rare case of Preiser's disease. J Bone Joint Surg Br 2009;91(10):1400-1402 
10 Lenoir H, Coulet B, Lazerges C, Mares O, Croutzet P, Chammas M. Idiopathic avascular necrosis of the scaphoid: 10 new cases and a review of the literature. Indications for Preiser's disease. Orthop Traumatol Surg Res 2012;98(04):390-397

11 Gambardella PC. Legg-Calvé-Perthes disease in dogs. In: Bojrab MJ, ed. Disease Mechanisms in Small Animal Surgery. 2nd edition. Philadelphia: Lippincott Williams \& Wilkins; 1993:804-807

12 Demko J, McLaughlin R. Developmental orthopedic disease. Vet Clin North Am Small Anim Pract 2005;35(05):1111-1135, v

13 Pidduck H, Webbon PM. The genetic control of Perthes' disease in toy poodles-a working hypothesis. J Small Anim Pract 1978;19 (12):729-733
14 Evans HE, de Lahunta A. Miller's Anatomy of the Dog. 4th edition. St. Louis, Missouri: Elsevier Saunders; 2013

15 Tu YK, Bishop AT, Kato T, Adams ML, Wood MB. Experimental carpal reverse-flow pedicle vascularized bone grafts. Part I: the anatomical basis of vascularized pedicle bone grafts based on the canine distal radius and ulna. J Hand Surg Am 2000;25(01): 34-45

16 Kalainov DM, Cohen MS, Hendrix RW, Sweet S, Culp RW, Osterman AL. Preiser's disease: identification of two patterns. J Hand Surg Am 2003;28(05):767-778

17 Karantanas A, Dailiana Z, Malizos K. The role of MR imaging in scaphoid disorders. Eur Radiol 2007;17(11):2860-2871 